\title{
Index autorum
}

$(\mathrm{L})=$ Libri, $(\mathrm{R})=$ Recensores

Abbs,J. H. 199 Adelman, S. 113

Benguerel, A.-P. 113 Beyer, E. 154 (L) Bhatia, T. K. 62 Broad, D.J. 401 Böðvarsson, A. 393 (R)

Carre, R. 285

Carton, F. 127 (R)

Dressier, U. 137 (L)

Emerit, E. 425

Fiess, D. 398 (L) Fónagy, I 31 Forner,W. 129 (R) Francois, D. 234 (L)

Gandour,J. 241 Goujon, P. 320 (L) Grünig, B. 135 (R)

Hara,M. 396 (L) Heger, K. 135 (L) Heike, G. 158 (R) Hellberg, S. 395 (L) 
Ho, A. T. 353 Hogan,J. T. 275 Hughes, O. M. 199

James, A. R. 469 (R)

Kappner, E. O. 320 (R) Karch, D. 398 (R) Klausenburger,J. 129 (L) Koerner, E. F. K. 222 Kohler, K. 1 Kohler, K. 145, 148, 149,

158 (R) Kramer, W. 75 (R) Krámský,J. 137 (R)

Ladefoged, P. 469 (L) Lehiste, I. 145 (L) Lehiste, I. 142, 467 (R) Lindqvist-Gauffin, J. 161 Lindsay, P. 45 Lucci, V. 127 (L)

Maddieson, I. 241 Malécot, A. 45, 93 Malécot,A. 234 (R) Mangold, M. 467 (L) Mares, F. V. 137 (L) Matzen, R. 154 (L) Mrayatí, M. 285 
Oram,J. 321

Painter, C. 334 Pétursson, M. 169 Pétursson, M. 393 (L) Pétursson, M. 396 (R) Piirainen, I. T. 395 (R) Pike, E. V. 321 Pilch, H. 149 (L) Plotkin, V. Y. 81

Priestly, T. M. S. 268 Purcell, E. T. 142 (L)

Richman, M. 307 Richter, H. 149 (L) Rietveld, A. C. M. 320 (R) Romportl, M. 148 (L)

Stålhane Andrésen, B. 232

(R) Sundberg, J. 161

Ulbrich, H. 75 (L)

Vance, T.J. 368 Vanvik, A. 232 (L)

Wüthrich, H. 158 (L) 